\title{
Check and Specification of the Performance of EDS Systems Attached to the SEM by Means of a New Test Material EDS-TM002 and an Updated Evaluation Software Package EDS Spectrometer Test - Version 3.4.
}

\author{
Vasile-Dan Hodoroaba ${ }^{1}$, Mathias Procop ${ }^{2}$ and Vanessa Rackwitz ${ }^{2}$ \\ 1. BAM Federal Institute for Materials Research and Testing, Division 6.8 Surface Analysis and \\ Interfacial Chemistry, Berlin, Germany. \\ 2. IfG - Institute for Scientific Instruments, Berlin, Germany.
}

Four years ago BAM has made available via its webshop [1] a test material, EDS-TM001, as well as an accompanying software package, "EDX spectrometer check", to be employed by both EDS (energy dispersive spectrometer) users and manufacturers to check and specify, respectively, the performance of an EDS. [2] The synthetic material consisting in a thick hard coating of $\mathrm{C}, \mathrm{Al}, \mathrm{Mn}, \mathrm{Cu}$ and $\mathrm{Zr}$, deposited on a steel substrate and the software package developed especially in connection with the test material enable not only quick procedures for the EDS (periodical) characterization but are also in line with the international standard ISO 15632 "Microbeam Analysis - Selected instrumental performance parameters for the specification and checking of energy-dispersive X-ray spectrometers for use in electron probe microanalysis" [3]. Hence, (i) the spectrometer energy resolution (evaluated at the C K, Mn Ka, but also $\mathrm{Mn} \mathrm{L} \alpha, \mathrm{Cu} \mathrm{L} \alpha, \mathrm{Al} \mathrm{K}$ and $\mathrm{Zr} \mathrm{L} \alpha$ line energies), (ii) the calibration state of energy scale, and (iii) the Mn$\mathrm{L} \alpha / \mathrm{Mn}-\mathrm{K} \alpha$ intensity ratio (as a measure for the instrumental detection efficiency) are automatically calculated by the evaluation software "EDS Spectrometer Test" from only one $10 \mathrm{kV}$ spectrum of the EDS-TM001.

The high interest of EDS users (mainly in German-speaking countries) as well as of EDS manufacturers in the test material EDS-TM001 has motivated us, in close cooperation with AXO DRESDEN company (Dresden, Germany) to manufacture new batches of superior quality, providing nearly identical spectra as EDS-TM001, as well as to update the software with improved features. The new test material is called EDS-TM002, and provides excellent homogeneity and long-term stability, due to the advanced manufacturing technology: both the multilayer stack structure of one- and two-element thin layers deposited on a silicon substrate contributes significantly to the superior homogeneity; the top carbon thin layer confers significant protection against surface oxidation.

As far as the evaluation software package is concerned, the effect of the detector temperature on the mean ionization energy is considered in the updated version 3.4, so that $\mathrm{Si}(\mathrm{Li})$ and SDD detectors are more realistically evaluated. Furthermore, detailed installation guide and help files are offered in German, and English. Administrator rights are no more necessary to use the software. Moreover, the software checks now whether the counting statistics is sufficient. A warning message recommends prolonged acquisition if the $\mathrm{C}-\mathrm{K}$ peak height is less than 5000 counts.

Progress on developments of another new test material designed to the performance check of X-ray spectrometers in the low energy range below $1 \mathrm{keV}$ will be also presented. 


\section{References:}

[1] www.webshop.bam.de (Product: Reference materials, Category: Test materials).

[2] M Procop and V-D Hodoroaba, Microsc Microanal 15(Suppl 2) (2009), p. 1120.

[3] ISO 15632:2012, "Microbeam Analysis - Selected instrumental performance parameters for the specification and checking of energy-dispersive X-ray spectrometers for use in electron probe microanalysis", ISO: Geneva.

[4] Thanks are due to European Metrology research Programme (EMRP) for funding the SurfChem project (http://www.emrp-surfchem.bam). The EMRP is jointly funded by the EMRP participating countries within EURAMET and the European Union.

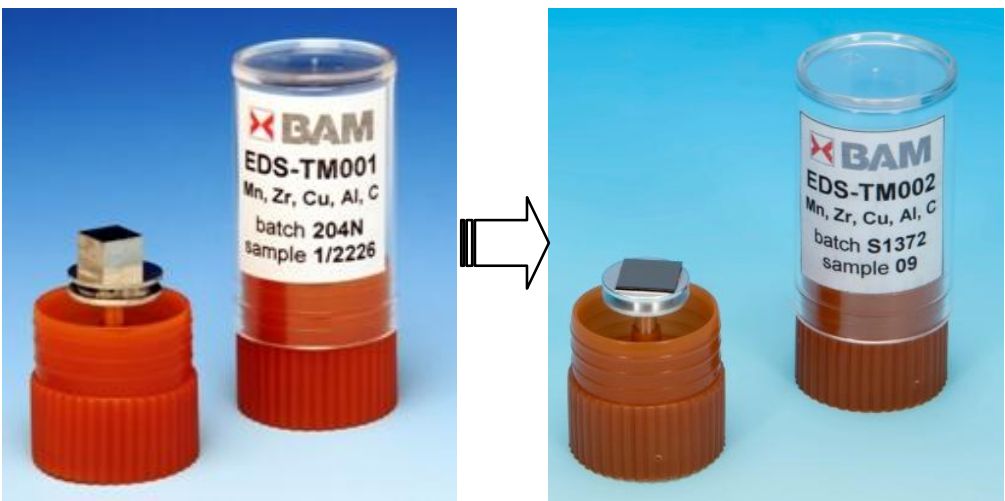

Figure 1. Photographs of EDS-TM001 (left) and of its follow-up EDS-TM002 (right).

Figure 2. Screenshot with the GUI of the updated evaluation software "EDS Spectrometer Test", version 3.4 (bottom).



